Kathleen G. Waller Robert W. Shaw

Department of Obstetrics and Gynaecology, University of Wales

College of Medicine,

Cardiff, United Kingdom

\title{
Risk Factors for Endometriosis: Menstrual and Life-Style Characteristics
}

\section{Key Words}

Endometriosis

Epidemiology

Causation

\begin{abstract}
Objective: To investigate possible risk factors for the development of endometriosis. Study Design: A case control study of 147 women with a new diagnosis of endometriosis, and 131 normal controls recruited from well women clinics. Controls were screened for the presence of symptoms of endometriosis. The setting was two tertiary referral centres for endometriosis and surrounding community clinics. Results: There was a significant positive association between double protection at menses and endometriosis ( $\mathrm{OR}=3.1)$, and a significant trend for cases to have shorter menstrual cycles. There was a greatly increased risk of endometriosis in those with an affected firstdegree relative. Conclusions: Menstrual patterns producing a greater number of bleeding days are shown to be associated with a greater risk of endometriosis.

With a greater ri
\end{abstract}

\section{Introduction}

Low parity and high social class have long been considered to be important risk factors for the development of endometriosis [1-3]. Recent studies have shown that menstrual factors such as irregular/long menstrual cycles are associated with a reduced risk of endometriosis $[4,5]$. An increase in the number of days of bleeding during menses has also been shown to increase the risk of endometriosis [6, 7]. If it is the case that endometriosis is associ- ated with menstrual patterns producing a greater number of bleeding days, it seems likely that transtubal flow of endometrial cells is an important factor in the aetiology of the disease.

A significant level of exercise has been shown to decrease the risk of endometriosis in one large study [6]. Concerning other factors which may influence oestrogen levels, including smoking and body weight, the evidence is conflicting [8, 9]. Data on contraceptive habits is of central importance [10], but studies

\begin{tabular}{ll}
\hline KARGER & $\begin{array}{l}\text { (1) 1998 S. Karger AG, Basel } \\
\text { 1011-7571/98/0072-0127\$15.00/0 }\end{array}$ \\
$\begin{array}{l}\text { Fax +41 61 306 1234 } \\
\text { E-Mail karger@karger.ch } \\
\text { www.karger.com }\end{array}$ & $\begin{array}{l}\text { This article is also accessible online at: } \\
\text { http://BioMedNet.com/karger }\end{array}$
\end{tabular}

Prof. R.W. Shaw

Department of Obstetrics and Gynaecology

University of Wales College of Medicine, Heath Park

Cardiff, CF4 4XN (UK)

Tel. +44 01222 743235, Fax +4401222 743722 
on sexual practises and endometriosis are lacking. Nichols and Lamb [11] in 1987 suggested that patients with endometriosis were more likely than controls to suffer from atopic disease, particularly hay fever. The prevalence of atopic disease in women with endometriosis is further investigated in the present study. The effects of other social habits such as caffeine and alcohol use have been little studied. However, the risk of endometriosis in assoication with infertility was found to be higher in women with moderate alcohol intake [12]. Few studies to date have screened control groups for the likely presence of endometriosis.

\section{Materials and Methods}

All participants in the study were asked to complete a self-administration questionnaire, which was designed to obtain data on lifelong menstrual patterns, social habits, sexual and contraceptive practices, as well as family history. Ethical approval was obtained from the hospitals concerned. All cases except 1 who were approached agreed to participate, and less than $2 \%$ of the controls who were approached refused.

\section{Cases}

These were recruited as a consecutive series from September 1991 until March 1992 at the Royal Free Hospital, London and then from April 1992 until May 1993 at the University of Wales College of Medicine. Power studies were performed which showed that in order to detect odds ratios of 2.0 or 0.5 with $80 \%$ power, 140 cases and controls were required. This was for factors with $10 \%$ or higher prevalence. Cases consisted of 147 women with a new laparoscopic or laparotomically confirmed diagnosis of endometriosis, or a new diagnosis of endometriosis within the preceding 12 months. In the latter cases all data were collected concerning the patient at the time of diagnosis. One hundred and eight patients were recruited from the University of Wales College of Medicine or the Royal Free Hospital, and 39 cases were recruited from the Endometriosis Society. For these cases, the gynaecologist who made the diagnosis of endometriosis was contacted and the stage of endometriosis confirmed from the operation record. The American Fertility
Society 1985 classification of endometriosis [13] was used throughout.

Eighty $(54.4 \%)$ of cases complained of pain only, and $59(40.1 \%)$ of women had a primary complaint of infertility. Eight cases (5.4\%) included women with endometriosis found incidently at sterilisation, or women in whom an asymptomatic ovarian cyst was histologically proven to be an endometrioma.

\section{Controls}

These were normal healthy women attending well women or family planning clinics for routine cytology, or for advise about starting or re-starting contraception. Controls were not matched singly, but were broadly comparable in terms of 5-year age groups. Controls were discounted if they were already using hormonal methods of contraception such as the combined oral contraceptive pill, the progesterone only pill or long-acting injectable progestagens, as these medications affect the character of menses. Seventeen controls were included who were admitted for laparoscopy for infertility and who had a normal pelvis, and whose partners were judged to be infertile.

If only patients undergoing laparoscopy were used as controls we would have a biased group, since patients only undergo laparoscopy for specific reasons such as pain, infertility or to be sterilized. However, it is not ethically feasible to exclude endometriosis in controls by performing laparoscopy. Questions specifically concerning dysmenorrhoea, dyspareunia and pelvic pain were included in the questionnaire. Controls were excluded $(n=6)$ if they complained of severe dysmenorrhoea, moderate or severe pelvic pain or severe dyspareunia. Symptomatic endometriosis in controls was therefore excluded as far as possible, but it is recognised that asymptomatic endometriosis could still be present in some control subjects.

\section{Statistical Analysis}

Odds ratios (OR) were computed, together with their 95\% confidence intervals (CI) using Confidence Interval Analysis version 1.0 software. For factors classified at more than two levels, the Mantel test was used to assess for linear trend. It was recognised that cases and controls were not ideally matched in terms of marital status, and therefore odds ratios were adjusted where necessary for this variable. Menstrual factors and parity were included in a logistic regression model including terms for marital status, length of menses, cycle length, and parity, which were considered to be potential confounding variables. Stata version 4.0 was used to calculate adjusted odds ratios. 


\section{Results}

The stage of endometriosis for the group of 147 cases according to the Revised American Fertility Society Classification of 1985 was as follows: $83(56.5 \%)$ had minimal (stage I) disease, $26(17.7 \%)$ had mild (stage II) disease, $18(12.2 \%)$ had moderate (stage III) and 20 $(13.6 \%)$ had severe (stage IV) disease. The mean age at diagnosis was 31.7 years $(\mathrm{SD}=$ 6.0) for minimal disease, 33.3 years $(\mathrm{SD}=6.7)$ for mild disease, 33.3 years $(\mathrm{SD}=6.8)$ for moderate and 34.2 years $(\mathrm{SD}=6.7)$ for severe disease. Almost all the women in the study were Caucasian, 9 controls and 10 cases were non-Caucasian. The demographic profile of cases and controls is shown in table 1. In all the tables, if the number of missing values is large, this is stated. Cases of endometriosis tended to be married more often than controls, this represents a selection bias because $59(40.1 \%)$ of cases presented seeking treatment for infertility. Cases and controls were not significantly different in terms of social class and educational achievement.

Table 2 shows adjusted odds ratios for menstrual characteristics and parity. There was no difference between cases and controls in age at menarche. There was, however, a significant trend towards cases having shorter menstrual cycles than controls $\left(\chi^{2}=4.51, p=0.03\right)$. There was no significant difference in the length of menses between cases and controls. Concerning menstrual protection, there was less use of tampons amongst cases (adjusted $\mathrm{OR}=0.5, \mathrm{CI}$ $=0.2-1.0$ ). There was a significant positive association between double protection at menses and endometriosis, adjusted $\mathrm{OR}=3.1$ $(\mathrm{CI}=1.2-7.8)$. Women with endometriosis were of significantly lower parity than controls, for parity of 2 or greater the adjusted $\mathrm{OR}=0.3$ $(\mathrm{CI}=0.1-0.6)$ compared with nulliparous women. Seventeen cases and 13 controls had suffered one or more spontaneous abortions
Table 1. Demographic profile of cases and controls

\begin{tabular}{lccl}
\hline & Controls & Cases & OR $(\mathrm{CI})$ \\
\hline Age, years & & & \\
$\quad 224$ & 26 & 12 & \\
$25-29$ & 35 & 38 & \\
$30-34$ & 31 & 52 & \\
$35-39$ & 22 & 20 & \\
$40-44$ & 10 & 17 & \\
$\quad 745$ & 7 & 8 & \\
\hline Marital status & & & \\
Single & 44 & 27 & \\
Married & 57 & 102 & \\
Living together & 17 & 13 & \\
Other & 13 & 5 & \\
\hline Social class ${ }^{1}$ & & & \\
1 (professional) & 9 & 11 & 1.0 \\
2 (intermediate) & 32 & 47 & $1.2(0.4-3.2)$ \\
3 (skilled) & 51 & 60 & $1.0(0.4-2.5)$ \\
$4 / 5$ (non-skilled) & 12 & 11 & $0.8(0.2-2.5)$ \\
$\chi^{2}$ trend & & & 0.67 \\
Others & 27 & 18 & \\
\hline Education & & & \\
Above 18 years & 48 & 44 & 1.0 \\
To 18 years & 17 & 15 & $1.0(0.4-2.1)$ \\
To 16 years & 38 & 60 & $1.7(1.0-3.1)$ \\
No qualifications & 22 & 16 & $0.8(0.4-1.7)$ \\
$\chi^{2}$ trend & & & 0.37 \\
\hline 1 Office of Population Censuses and Surveys [17]. \\
\hline
\end{tabular}

$(\mathrm{OR}=1.2, \mathrm{CI}=0.5-2.6)$. Seventeen cases and 23 controls had had one or more terminations of pregnancy $(\mathrm{OR}=0.6, \mathrm{CI}=0.3-1.2)$.

There was also no difference between cases and controls in the age at first birth (table 3). There was no relation between age at coitarche or lifetime partners and endometriosis, and intercourse during menses does not appear to have a positive association with endometriosis. Use of the oral contraceptive pill (OCP) was not associate with a changed risk of endometriosis. Sixteen cases and 15 con- 
Table 2. Endometriosis; Menstrual characteristics and parity

\begin{tabular}{|c|c|c|c|c|}
\hline & A & $\mathrm{B}$ & $\mathrm{OR}(\mathrm{CI})$ & $\begin{array}{l}\text { OR }(\mathrm{CI}) \\
\text { adjusted }^{1}\end{array}$ \\
\hline \multicolumn{5}{|l|}{ Menarche, years } \\
\hline$\gtrless 11$ & 24 & 29 & 1.0 & 1.0 \\
\hline $12-13$ & 62 & 83 & $1.1(0.6-2.1)$ & $1.0(0.5-2.0)$ \\
\hline$\geqslant 14$ & 45 & 35 & $0.6(0.3-1.3)$ & $0.6(0.3-1.3)$ \\
\hline$\chi^{2}$ trend & & & & 2.12 \\
\hline \multicolumn{5}{|l|}{ Cycle length, days } \\
\hline$\gtrless 27$ & 21 & 40 & 1.0 & 1.0 \\
\hline $28-34$ & 94 & 92 & $0.5(0.3-0.9)$ & $0.5(0.3-1.0)$ \\
\hline$\geqslant 35$ & 13 & 11 & $0.4(0.2-1.2)$ & $0.4(0.2-1.3)$ \\
\hline$\chi^{2}$ trend & & & & 4.51 \\
\hline \multicolumn{5}{|c|}{ Length of menses, days } \\
\hline$<3$ & 16 & 17 & 1.0 & 1.0 \\
\hline $4-6$ & 100 & 99 & $0.9(0.4-2.0)$ & $1.0(0.5-2.3)$ \\
\hline$\geqslant 7$ & 15 & 31 & $2.0(0.8-4.9)$ & $2.5(0.9-6.9)$ \\
\hline$\chi^{2}$ trend & & & & 2.60 \\
\hline \multicolumn{5}{|l|}{ Menstrual protection } \\
\hline Towels & 34 & 49 & 1.0 & 1.0 \\
\hline Tampons & 61 & 43 & $0.5(0.3-0.9)$ & $0.5(0.2-1.0)$ \\
\hline Single protection & 123 & 122 & 1.0 & 1.0 \\
\hline Double protection & 8 & 25 & $3.1(1.4-7.3)$ & $3.1(1.2-7.8)$ \\
\hline \multicolumn{5}{|l|}{ Parity } \\
\hline 0 & 76 & 95 & 1.0 & 1.0 \\
\hline 1 & 15 & 22 & $1.2(0.6-2.4)$ & $0.7(0.3-1.7)$ \\
\hline$\geqslant 2$ & 40 & 30 & $0.6(0.3-1.1)$ & $0.3(0.1-0.6)$ \\
\hline$\chi^{2}$ trend & & & & 2.64 \\
\hline
\end{tabular}

$\mathrm{A}=$ Controls $; \mathrm{B}=$ cases. $* \mathrm{p}=0.03$.

1 Derived from logistic regression model including terms for marital status, parity, cycle length and length of menses. trols had ever used the intra-uterine contraceptive device $(\mathrm{IUCD} ; \mathrm{OR}=1.0$ compared with never use, $\mathrm{CI}=0.5-2.0$ ).

There were no differences between cases and controls in current and lifetime smoking and exercise habits (table 4). There was also no relation between body mass index and endometriosis, and caffeine intake and endometriosis. There was a significant trend for lower alcohol consumption amongst cases $\left(\chi^{2}=3.75, p=0.05\right)$.
Twelve cases and 21 controls reported that they suffer from asthma (OR $=0.5, \mathrm{CI}=0.2$ 1.0). Twenty-five cases and 17 controls had excema $(\mathrm{OR}=1.4, \mathrm{CI}=0.7-2.7)$, and 30 cases and 16 controls had hay fever $(\mathrm{OR}=1.8$, $\mathrm{OR}=1.0-3.6)$. When the presence of any atopic factor was considered, i.e. asthma, excema or hay fever, 51 cases had at least one atopic illness and 43 controls also did $(\mathrm{OR}=$ $1.1, \mathrm{CI}=0.7-1.8)$. There were significantly more women with a positive family history of endometriosis (in mother or a sister) amongst 
Table 3. Endometriosis; Pregnancy details and sexual factors

\begin{tabular}{|c|c|c|c|}
\hline & Controls & Cases & $\mathrm{OR}(\mathrm{CI})$ \\
\hline \multicolumn{4}{|c|}{ Age first live birth ${ }^{1}$} \\
\hline$<22$ & 22 & 21 & 1.0 \\
\hline $23-28$ & 23 & 22 & $1.0(0.5-2.3)$ \\
\hline$\geqslant 29$ & 8 & 7 & $0.9(0.3-3.0)$ \\
\hline$\chi^{2}$ trend & & & 0.01 \\
\hline \multicolumn{4}{|c|}{ Age coitarche, years } \\
\hline$\gtrless 15$ & 19 & 6 & 1.0 \\
\hline $16 / 17$ & 28 & 57 & $6.5(2.3-17.9)$ \\
\hline$\geqslant 18$ & 60 & 67 & $3.5(1.3-9.4)$ \\
\hline$\chi^{2}$ trend & & & 0.95 \\
\hline No answer & 24 & 17 & \\
\hline \multicolumn{4}{|c|}{ Lifetime partners ${ }^{1}$} \\
\hline $0-1$ & 34 & 48 & 1.0 \\
\hline $2-4$ & 42 & 54 & $0.9(0.5-1.7)$ \\
\hline $5-9$ & 24 & 23 & $0.7(0.3-1.4)$ \\
\hline$\geqslant 10$ & 25 & 18 & $0.5(0.2-1.1)$ \\
\hline$\chi^{2}$ trend & & & 3.63 \\
\hline No answer & 6 & 4 & \\
\hline \multicolumn{4}{|c|}{ Intercourse during menses } \\
\hline Never & 64 & 68 & 1.0 \\
\hline Occasionally & 53 & 54 & $1.0(0.6-1.6)$ \\
\hline$\geqslant$ once/menses & 9 & 11 & $1.2(0.5-3.0)$ \\
\hline$\chi^{2}$ trend & & & 0.01 \\
\hline No answer & 5 & 14 & \\
\hline \multicolumn{4}{|l|}{ OCP use, years } \\
\hline Never & 39 & 37 & 1.0 \\
\hline$<5$ & 43 & 43 & $1.1(0.6-2.0)$ \\
\hline $5-9$ & 37 & 44 & $1.3(0.7-2.4)$ \\
\hline$>10$ & 11 & 20 & $1.9(0.8-4.5)$ \\
\hline$\chi^{2}$ trend & & & 2.11 \\
\hline
\end{tabular}

cases $(n=16)$ than controls $(n=3)$, but as few women reported a family history where the confidence intervals are large $(\mathrm{OR}=4.9 ; \mathrm{CI}=$ 1.4-17.4).

\section{Comment}

This study shows that the use of double protection during menses and low parity are significantly associated with endometriosis. Darrow et al. [7] in 1993 found that heavy menstrual flow was significantly associated with endometriosis $(\mathrm{OR}=2.5)$ in women under 30 years of age as compared with friend controls. Cramer et al. [6] in 1986 did not find that the use of double protection was significantly associated with endometriosis, possibly because they did not separate those who used towels and tampons on separate occasions from those women who used double protection to prevent flooding.

Cramer et al. [6] found longer menses to be significantly associated with endometriosis; women with a menstrual flow of 8 days or longer had an increased risk of endometriosis (relative risk, RR = 2.4). Darrow et al. [7] found elevated risks for menstrual flow of 6 or more days per month $(\mathrm{OR}=2.5)$ in women under 30 years of age. No significant association was found between endometriosis and longer menses in this study. A short menstrual cycle length of 27 days or less was significantly associated with endometriosis in the study by Cramer et al. [6] of 1986 ( $R R=2.1$ compared with cycle length 28-34 days). In our study there was a significant trend for shorter menstrual cycles in cases. An early age at menarche was not associated with an increased risk of endometriosis in the present study, but Paparazzini et al. [4] in 1991 found that menarche at aged 15 years or above was associated with a decreased risk of endometriosis. Low parity was found to be significantly associated with endometriosis in the present study, although $40.1 \%$ of cases were infertile and therefore a selection bias exists. However, low parity has been found to be a risk factor for endometriosis in almost all other case control studies, even when infertile women are considered separately in the analysis [5].

There was less use of tampons as a method of menstrual protection amongst cases in the present study, but this was of borderline signif- 
Table 4. Endometriosis; Life-style variables

\begin{tabular}{|c|c|c|c|}
\hline & Controls & Cases & $\mathrm{OR}(\mathrm{CI})$ \\
\hline \multicolumn{4}{|c|}{ Current smoking } \\
\hline None & 94 & 108 & 1.0 \\
\hline$\gtrless 10$ & 14 & 8 & $0.5(0.2-1.2)$ \\
\hline $11-19$ & 12 & 17 & $1.2(0.6-2.7)$ \\
\hline$\geqslant 20$ & 11 & 14 & $1.1(0.5-2.6)$ \\
\hline$\chi^{2}$ trend & & & 0.06 \\
\hline \multicolumn{4}{|c|}{ Years of smoking } \\
\hline 0 & 71 & 83 & 1.0 \\
\hline $1-7$ & 22 & 14 & $0.5(0.3-1.1)$ \\
\hline$\geqslant 8$ & 37 & 50 & $1.2(0.7-2.0)$ \\
\hline$\chi^{2}$ trend & & & 0.12 \\
\hline \multicolumn{4}{|c|}{ Sport, h/week } \\
\hline 0 & 64 & 82 & 1.0 \\
\hline $1-2$ & 41 & 36 & $0.7(0.4-1.2)$ \\
\hline$\geqslant 3$ & 26 & 29 & $0.9(0.5-1.6)$ \\
\hline$\chi^{2}$ trend & & & 0.56 \\
\hline \multicolumn{4}{|c|}{ Sport length } \\
\hline 0 & 64 & 82 & 1.0 \\
\hline $1-4$ years & 34 & 20 & $0.5(0.2-0.9)$ \\
\hline$\geqslant 5$ years & 31 & 45 & $1.1(0.6-2.0)$ \\
\hline$\chi^{2}$ trend & & & 0.00 \\
\hline \multicolumn{4}{|c|}{ Body mass index, $\mathrm{kg} / \mathrm{m}^{2}$} \\
\hline$<20$ & 17 & 20 & 1.0 \\
\hline $20-25$ & 80 & 87 & $0.9(0.5-1.9)$ \\
\hline$>25$ & 26 & 34 & $1.1(0.4-2.5)$ \\
\hline$\chi^{2}$ trend & & & 0.12 \\
\hline \multicolumn{4}{|c|}{ Alcohol, units/week } \\
\hline 0 & 52 & 71 & 1.0 \\
\hline $1-9$ units & 51 & 57 & $0.8(0.5-1.4)$ \\
\hline$\geqslant 10$ units & 28 & 19 & $0.5(0.2-1.0)$ \\
\hline$\chi^{2}$ trend & & & 3.75 \\
\hline \multicolumn{4}{|c|}{ Caffeine, units/day ${ }^{\mathrm{b}}$} \\
\hline 0 & 9 & 7 & 1.0 \\
\hline $1-7$ units & 90 & 97 & $0.7(0.3-2.0)$ \\
\hline$\geqslant 8$ units & 4 & 27 & $1.4(0.5-4.1)$ \\
\hline$\chi^{2}$ trend & & & 3.11 \\
\hline \multicolumn{4}{|c|}{$* \mathrm{p}=0.05$} \\
\hline a $\quad$ OR adj & $\mathrm{r}$ marital st & atus. & \\
\hline b $\quad$ Unit $=$ & $\mathrm{ea} / \mathrm{coffee} / \mathrm{co}$ & & \\
\hline
\end{tabular}

icance. Darrow et al. [7] in 1993, however, found long-term tampon use (14 years or greater) to be a risk factor for endometriosis $(\mathrm{OR}=$ 3.6) in women under 30 years of age. Lamb and Berg [14] in 1985 and Cramer et al. [6] found that tampon users were not at altered risk.

Cramer et al. [6] found that heavy smoking since school days lessened the chances of developing endometriosis, and it was postulated that this was because of lowered endogenous oestrogen levels. Women who exercised intensively were also shown to be at lower risk. These factors were not confirmed as having a significant relationship with endometriosis in the present study. We also found no relationship between endometriosis and body mass index. Darrow et al. [7] in their study in 1993 also found no relationship, but Paparazzini et al. [4] noted an inverse relationship between body mass index and the risk of ovarian endometriomas.

Grodstein et al. [12] in 1994 reported that the risk of endometriosis in association with infertility was higher in women with moderate alcohol consumption $(\mathrm{OR}=1.6)$. In the present study, it appears that there is a trend of borderline significance such that alcohol consumption tends to be lower amongst cases. The reason for this difference from other studies is not clear.

There is also no relationship between endometriosis and social class and education in this study, which refutes the evidence available from older studies [1] and more recent case control studies [3-5]. Our results could reflect equal access for all to health care in the United Kingdom.

The use of contraception does not appear to modify the risk of endometriosis, although some bias may have occurred as controls were specifically excluded if they were using hormonal contraception. However, $40.1 \%$ of cases were infertile and would not been practising contraception either. Evidence concerning both the OCP and the IUCD is conflicting 
[10]. Vessey et al. [15] in 1993 reported that current use of the combined pill appeared to decrease the risk of endometriosis $(\mathrm{RR}=0.4)$ but that the risk was increased when former users were compared with never users $(\mathrm{RR}=$ 1.8). Oral contraceptives appeared to temporarily suppress endometriosis. A similar picture emerged for use of the IUCD.

In our study the increased risk of endometriosis was nearly 5 -fold in women who had first-degree relatives with the disease $(\mathrm{OR}=$ 4.9, $\mathrm{CI}=1.4-17.4)$. Moen and Magus [16] in 1993 found a 7 -fold increased risk of developing the disease for first-degree relatives of 515 women with endometriosis $(\mathrm{OR}=7.2, \mathrm{CI}=$ 2.1-24.3). Severe manifestations of the disease were found more often in those women with a positive family history compared to those with no such history. The increased risk was less in this study, but many women who did not admit to a family history of endometriosis stated that first-degree relatives had undergone gynaecological surgery, such as ovarian cystectomy. It is possible that the medical records for such relatives would have shown that they also had endometriosis.

We found more women with hay fever amongst cases, which agrees with the work of Nichols et al. [11]. There were, however, fewer cases of asthma amongst cases. If there was a relationship between atopy and endometriosis, it would be expected that there would be more cases than controls with asthma, moreover there would be more cases with any atopic condition.

In conclusion it appears that woman of low parity with heavy menses, requiring double protection, and a family history of endometriosis may be at increased risk of developing the disease.

\section{References}

1 Houston DE: Evidence for the risk of pelvic endometriosis by age, race and socioeconomic status. Epidemiol Rev 1984;6:167-191.

2 Makhlouf Obermeyer C, Armenian HK, Azoury R: Endometriosis in Lebanon: A case-control study. Am J Epidemiol 1986;124:762-767.

3 Arumugam K, Welluppilai S: Endometriosis and social class: An Asian experience. Asia-Oceania J Obstet Gynaecol 1993;19:231-234.

4 Paparazzini F, La Vecchia C, Franceschi S, Negri E, Cecchetti G: Risk factors for endometrioid, mucinous and serous benign ovarian cysts. Int J Epidemiol 1989;18:108-112.

5 Candiani GB, Danesino V, Gastaldi A, Parazzini F, Ferraroni M: Reproductive and menstrual factors and risk of peritoneal and ovarian endometriosis. Fertil Steril 1991;56: 230-234.

6 Cramer DW, Wilson E, Stillman RJ, Berger MJ, Belisle S: The relation of endometriosis to menstrual characteristics. JAMA 1986;255:19041908.
7 Darrow SL, Vena JE, Batt RE, Zielezny MA, Michalek AM, Selman S: Menstrual cycle characteristics and the risk of endometriosis. Epidemiology 1993;4:135-142.

8 Vercellini P, Crosignani PG: Epidemiology of endometriosis; in Brosens I, Donnez J (eds): The Current Status of Endometriosis Research and Management. Proc 3rd World Congr on Endometriosis, Brussels, June 1992. Carnforth, Parthenon, 1992, pp 111-130.

9 McCann SE, Freudenheim JL, Darrow SL, Batt RE, Zielezny MA: Endometriosis and body fat distribution. Obstet Gynecol 1993;82:545549.

10 Vercellini P, Ragni G, Trespidi L, Oldani S, Crosignani PG: Does contraception modify the risk of endometriosis? Hum Reprod 1993;8: 547-551.
11 Nichols TR, Lamb K, Arkins JA: The association of atopic diseases with endometriosis. Ann Allergy 1987;59:360-363.

12 Grodstein F, Goldman MB, Cramer DW: Infertility in women with moderate alcohol use. Am J Public Health 1994;84:1429-1432.

13 American Fertility Society: Revised American Society Classification of Endometriosis. Fertil Steril 1985. 43:351-352.

14 Lamb K, Berg N: Tampon use in women with endometriosis. J Community Health 1985;10:215-225.

15 Vessey MP, Villard-Mackintosh L, Painter R: Epidemiology of endometriosis in women attending family planning clinics. BMJ 1993;306: 182-184.

16 Moen MH, Magnus P: The familial risk of endometriosis. Acta Obstet Gynecol Scand 1993;72:560-564.

17 Office of Population Censuses and Surveys: Classification of Occupations. London, HMSO, 1980. 